\title{
Challenges Faced by Racial Minority Students at Justus-Liebig University, Germany and North-West University, South Africa
}

\author{
Didimalang Matsheka $^{1} \&$ Tendayi Garutsa ${ }^{1}$ \\ ${ }^{1}$ Sociology Department, North West University, South Africa \\ Correspondence: Tendayi Garutsa, Sociology Department, Mafikeng Campus, North West University, South Africa.
}

Received: November 15, 2021

Accepted: January 24, 2022

Online Published: January 24, 2022

doi:10.5430/ijhe.v11n7p13

URL: https://doi.org/10.5430/ijhe.v11n7p13

\begin{abstract}
Educational institutions are characterised by cultural and institutional racism that is embedded in their structural systems, curriculum and practices that negatively impact the social and academic experiences of racial minority students. Prejudice and discrimination are rooted in hierarchies whereby some cases evidence one directional oppression of a racial group by the dominant or majority group. The study aimed at exploring challenges faced by racial minority students at Justus-Liebig University and North-West University. The study utilized a qualitative research approach in order understand the opinions, experiences and views of racial minority students about their campus realities. Fourteen in-depth interviews were undertaken with racial minority students and findings were analysed through content thematic analysis. The findings revealed that challenges faced by minority racial students from Justus-Lieberg University and North West University were similar. The challenges include but are not limited to; difficulties with interaction with the racial majority group, academic stressors like failure to adapt to high workload, adaptation to the academic climate, language and cultural barriers. This study calls for the development of new policies that pursue a restructuring of the campus environment to make it beneficial to all students. There is a need for universities to establish and maintain inclusive educational programs and policies that can assist minority students to be integrated into the academic systems.
\end{abstract}

Keywords: racial minority students, inclusive, race

\section{Introduction}

Vast information exists on the subject of minority students in predominately-white institutions (Jayakumar, 2015; Isla-Land, 2015; Lo, et al., 2017; Okusolubo, 2018). The intake of racial minority students was a strategy to diversify the universities. The admission processes were simplified in order to accommodate diverse racial groups. Academic and social experiences were perceived to be fundamental determinants of student's integration in institutions of higher learning (Morshedi, 2011). Scholarly research on student minority groups vary from one country to another. The research provides robust evidence of racial minority students experiencing negative campus settings. These often take the form of significantly higher student dropout rates as well as greater barriers of social and academic integrations than the majority population. To exacerbate the situation of racial minority students, the outbreak of coronavirus pandemic brought out social and racial inequalities in the education system. Schools and universities were closed with 1.6 billion learners were affected across 194 countries, accounting for more than $90 \%$ of total enrolled learners (UNESCO, 2020). Trammell et al., (2021) further advance that the psychosocial impacts of COVID-19 in educational settings varied by race although mental responses tended to be universal. Oliranin and Uleanya (2021) stressed that the outbreak of COVID-19 pandemic has severe impacts on international students with most Racial minority students (RMS) constituting the larger part of this group than those of the host countries. With long existing racial and socio-economic inequalities, COVID-19 has likely worsened the inequalities experienced by racial minority groups.

Education remains unequal across the globe even though equality in educational institutions is fundamental for all population groups. Indeed, South African universities are moving away from an elite racially divided system evidenced by institutions of higher learning having become increasingly diverse due to demographic and educational policy changes in an effort to increase the underrepresented racial groups (Odhav, 2009). These have led to increased diversity and historical process of providing students with full access to higher education (Odhav, 2009). Students from different backgrounds add a great deal of cultural and intellectual diversity to university campuses (Ritter, 2016; Zhao, et al., 2005). Marmer, et al. (2010) argue that institutions of higher learning contribute significant ideas, values and production to society. Due to apartheid policies in South Africa, the education system was racialized. Through 
overt racist policies, many black students faced discrimination (Odhav, 2009). On the other hand, countries such as Germany were rooted in power relations (sovereignty countries) as they possessed power and dominion over the African countries (Marmer, et al. 2010). Across the globe, race was used as an organizing principle to normalise racial segregation in different societal structures. Minority students were more exposed to structural racism, violence and alienation. A study conducted by the European Union Minorities and Discrimination Survey (2000) reports that black people in Germany are extremely exposed to criminalization, physical attacks and unfair treatment in public places such as academic sectors namely, universities, schools and colleges (Marmer, et al., 2010). Similar to South Africa, black students especially those from a poor background, experienced severe segregation. Because of racial segregation, only a few black students enrolled at institutions of higher learning (Mahlangu, 2017:33).

The rationale for the selection of Justus-Liebig University (JLU) and North-West University (NWU) Mahikeng campus were that, the former is a predominately-white institution, while the latter is a campus formed from a historically black institution. Therefore, these two varying contexts provided a basis for studying and understanding racial minority students' experiences. Non-white dominated institutions like the case of NWU: Mahikeng campus, the racial minority group (white students), though without numerical majority, have white privilege over the non-white majority. On the other hand, a white dominated institution of higher learning like JLU where whites are the numerical majority and the non-white students are the the racial minority students coupled with their status as immigrants, might also affect their social and academic experiences. The history of NWU Mahikeng campus poses challenges towards the integration of racial minority students. Between 2011 and 2017, 91\% of the student population on Mahikeng Campus was made up of black students, while a meagre 8\% were white students (NWU Annual report, 2017). As it is, this campus provides a unique platform to understand the experiences of racial minority students in institutions of higher learning. Comparatively, JLU which is located in Germany, and had a 40\% intake of students from other parts of Europe, while the intake of students from other parts of the world increased to approximately 28000 students including international students (Frink, 2000).

\section{Research Aim}

This paper explored the challenges faced by racial minority students at JLU and NWU. More specifically, the study sought to establish the social and academic experiences of JLU and NWU racial minority students' environments.

\section{Theoretical Framework}

This paper is anchored in the racial micro aggressions theory. According to Pandher (2017:3), Chrester Pierce used the term micro aggression in 1970. The author defined it as "the most grievous of offensive mechanisms spewed at victims of racism and sexism is micro-aggressions. These are subtle, innocuous, preconscious, or unconscious degradations, and putdowns, often kinetic but capable of being verbal and or kinetic. In and of itself a micro-aggression may seem harmless, but the cumulative burden of a lifetime of micro-aggressions can theoretically contribute to diminished mortality, augmented morbidity, and flattened confidence" (Pierce, 1995: 281). Additionally, Lilienfeld (2017:139) states that micro aggressions were defined by all insults, subtle snubs, which are directed towards the minority populations.

Solorzano, et al. (2001) outlines that racial micro-aggressions are verbal and non-verbal activities seen as insults directed towards an individual or a group of people. In effect, such behaviours, gestures or actions can be direct and indirect. Non-verbal communications are equally important as verbal communications. It is evident that in most cases, dominant groups often use their positions to justify their actions towards the minority groups. In other words, factors such as race are socially constructed and are used to differentiate and separate groups. The racial micro-aggressions theory argues that other races portray other racial groups either as superior or inferior. Sue, et al. (2007:271) concurs with the statement above, based on the belief that "racial micro-aggressions are brief and common place daily verbal, behavioural or environmental indignities, whether intentional or slights and insults toward people of color"

Sue, et al. (2017) argued that the types of micro-aggressions that are most likely to occur are, micro-assault, micro-insulation and micro-invalidations. An individual determines these micro-aggressions. People who insult can make such remarks unconsciously, in which they do not realise the damage their comments cause. Sue et al, (2007:275) highlighted that they are, "nine categories of micro-aggressions including; alien in one's own land, ascription of intelligence, color blindness, criminality or assumption of criminal status, denial of individual racism, myth of meritocracy, pathologising cultural values or communication styles, second-class-status, and environmental invalidation". All these convey different messages to the victim, thus causing the victim to feel alienated, discriminated, or isolated. For example, the in the ascription of intelligence, a white person conveys a message that insinuates that whites are more intelligent than blacks are. This plays out in institutions of higher learning when a lecturer questions the racial minority student's work in comparison to the student who can be identified in the racial dominant group. 
This theory further outlines that sometimes perpetrators of micro-aggressions are unaware that their questions or actions inflict others negatively. In reference to this, Furedi (2015) criticised the theory for holding people responsible for their unconscious actions and words while at the same time acknowledging that some actions are practiced unconsciously with no intention of harm.

The following section will discuss the methodology utilised for this study.

\section{Methodology}

A qualitative research approach was utilized in order understand the racial minority students multiple opinions, experiences and views about their campus realities (both positive and negative). Employing this method assisted in ascertaining the impact the university climate has on the racial minority students' growth and development (Langkos, 2014: 1-2). The population of this study were racial minority students who enrolled at JLU and NWU. Purposive and snowball sampling was used to select the respondents in two different institutions of higher learning until the researcher reached a point of data saturation after fourteen interviews- a situation where no new themes or constructs emerged. Etikan et al. (2016) noted that purposive sampling is the inclusion of a participant due to certain attributes and experiences that they have which are important to the research. Purposive and snowball sampling methods were used to select students enrolled at the JLU and NWU who were not part of the dominant racial groups. Snowball sampling was employed to enable the researcher to trace other racial minority students on both campuses. Students were chosen based on their availability and willingness to share the challenges they faced at each of the two universities. The aim was to select a sample that reflected the population of the racial minority student's characteristics.

This study employed in-depth interviews to gain comprehensive insights on the experiences of racial minority students. 7 students from JLU and seven students from NWU participated in interviews. Standardised open-ended interviews were conducted via Skype at JLU and face-to-face interviews were used for the NWU participants. Interviews allowed the researcher to probe further to understand racial minority students' experiences, challenges and different strategies that institutions of higher learning use to integrate students in their learning environment. The aim of the interview was to introduce the central question on which the information was required and thereafter allowed the interviewees to respond to it openly. These interviews consisted of open-ended questions in order to allow the participants to report their thoughts, feelings and experiences regarding challenges they face in institutions of higher learning. A guiding question was posed to research participants. The question was framed as follows; "What are the academic challenges do you experience as a racial minority student on and off campus?" This was aimed at steering the discussion towards the academic and social challenges RMS students faced in institutions of higher learning. The interviewee probed the research participants on their experiences at NWU a black dominated institution of higher learning and JLU a white dominated institution of higher learning. The open-ended question elicited idiosyncratic and subjective responses from the participant and was necessary to steer the participants towards the social and academic challenges they face on and off campus as racial minority students should they digress. In this study, the researcher probed or asked the same question in different words to ascertain the validity of some responses. The Interview questions assisted the researcher to understand at a deeper level the challenges racial minority students faced. Ethical clearance was sought from the NWU and JLU to carry out the study. Informed consent was obtained from the racial minority students participating in the study. Data was analysed through content thematic analysis and presented in interview excerpts and themes. During the transcription and translation process, the researchers familiarised themselves with the data and we noted that potential ideas that could be coded from each transcript. Afterwards we began the process of generating codes through a process of revisiting the data (Nowell, Norris et al 2017). During this process, the researchers engaged in reflexive writing and wrote analytical memos of the emerging themes as we examined how the thoughts and ideas evolved as we immersed more deeply with the data (Castleberry \& Nolen 2018). Afterwards the researchers sorted, collated and reviewed the emerging themes before writing up the final analysis and write-up of the report.

The following section will present the findings of the study

\section{Presentation of Findings}

\subsection{Challenges Encountered by Respondents at Justus-Liebig University and North-West University}

\subsubsection{Racial Slurs and Micro Assault in Shared Spaces}

Students enrol into universities with different attitudes towards other racial groups and this can result in either strong interaction or racial discrimination. Negative racial experiences such as discrimination can cause depression, low self-esteem, anxiety and social withdrawals. The study findings revealed that racial minority students at both NWU and 
JLU encountered racial slurs in shared spaces such as classrooms, residential areas and off-campus. An interesting point to note was that this did not cause students to resort to social isolation, withdrawals and feelings of helplessness.

The following participants had this to say when asked about their experiences,

"I have encountered alienation and racism. The first one that I have encountered was during the language course. I was discriminated by a student from Italy and I also experienced the same at a party in Eichendorffering. The other one was in the city centre, but I would say mostly on campus, but those had literally showed me discrimination it only happened once in class, then they later changed, I think they got it. I do not know what happened. They changed their behaviour" (JLU Interviewee Number 7, January2020)

"I can't say I experienced any direct racism or any racist engagements. Nevertheless, the one incident I have a recollection on was an off campus incident where a white Dutch guy was making jokes about how they colonised Africa. It wasn't really like targeted at me, but that was the only time that I felt like very uncomfortable in a racial setting" (JLU Interviewee Number 5, January 2020)

"Students are actually okay, the staff members are however another situation. Not the lectures particularly, I will say some support staff. I do not know what his problem was but whenever I would come, he would ask me questions which made feel uncomfortable. Especially because these incidents occurred when I was in a group and I would be singled out" (NWU Interviewee Number 1, February 2020).

Racial minority students from both contexts experienced subtle and open racism at their institutions both on and off campus. One student from JLU indicated that the perpetrators of racial slurs were mainly students unlike at NWU where the perpetrators were support staff. Moreover, one respondent from Justus-Liebig University added that some of the racial slurs and alienations occurred when they were off-campus. A point to note from both contexts was that some racial slurs were verbal and direct and others were subtle and or unconscious degradations. Nonetheless, no student indicated reporting racial incidents to the student support services; rather, they chose to let it go.

\subsubsection{Failure to Adapt to New Languages}

There is a direct relationship between race, language and racism. This interface influences the social organisation and behaviour of people in different systems. JLU and NWU respondents shared both their positive and negative experiences on how they adapt to new languages in international universities. For racial minority students, the learning of new languages goes beyond language proficiency and communication competency but also requires the students to learn about the culture, custom and beliefs embedded in that dominant language. The intersection of race and language in institutions of learning brings forth issues related to power, imperialism, and supremacy of the racial and linguistic domination of one culture to the other. For JLU students, the respondents experienced linguistic challenges and language barriers in and outside the institution. All racial minority students who were international students at JLU students enrolled in the compulsory German course. They experienced challenges in reading, grammar articulation and writing comprehension during their arrival. The main objective of the course was to assist the students not to face the language barrier in and outside the institution. In NWU, RMS who could not speak Setswana were not compelled to enrol in the Setswana course for beginners.

The effects of language standardisation in both contexts creates inequalities between in-group and outgroup students. Research participants said the following regarding adapting to new languages:

The German grammar is difficult to comprehend, I am glad I passed. I could not even engage in a flawless conversation. I studied to pass. I just know the basics. I think also think the problem comes with, most of the international students are used to speaking their home languages especially when they are together, maybe we could have tried to communicate in German, who knows, we were going to improve, but again, I am not sure, it's just a suggestion. But again, we only learned German in-class, and that was it". (JLU Interviewee Number 5, January 2020)

"All my classes were taught in English and I like it like that, although my home language is Afrikaans. I pass well and I have been doing English from my primary school, so I do not find it difficult at all. Last year when I was doing my first year, I was attending the AGLE classes which helped me with academic writing skills. I feel, I mean, I have improved. (NWU Interviewee Number 1, February 2020)

Findings indicated that RMS in JLU found it challenging to learn the German language. The module did not assist them to comprehend the language. All the respondents stated they found the language difficult to speak in JLU. Findings also showed that before the COVID-19 pandemic, RMS struggled to participate on equal terms in the classroom in the process of learning new languages. With the pandemic, they encountered the dual challenge of mastering content while continuing to learn and adapt to new languages. The shift to learning from home amid the challenges of the 
pandemic made adaptation more difficult. On the other hand, the RMS in NWU indicated that they used English to communicate since the university did not make it compulsory for all international and racial minority students to take Setswana classes. Again, the lack of willingness, time and funding experienced by students prevented enrolment into the introductory Setswana course.

\subsubsection{Adjusting to New Academic Contexts}

RMS students come from different educational contexts to institutions of higher learning. The transition is more difficult for RMS who are also international students to adjust to university life in the host country. RMS might encounter academic and social challenges in trying to adjust to the new environments, pedagogical approaches and cultural differences, which vary from one context to another and change overtime. Findings reveal that both RMS in JLU and NWU experienced academic stress due to high workloads and adaption to the new academic contexts during their first semester. Their lack of formal and informal interaction with the student majority groups consequently affected their integration. The following research participants had this to say:

"I would say that, first semester was difficult because I felt like I could not handle the work load. I was not used to how they gave us articles, many articles to read before class. If you fail to read these articles, it was difficult for you to take part in the class discussions. Furthermore, our modules required us to submit article summary reflections on the topic of discussion. I found it very challenging because it was a new learning approach. In a semester, we had four seminar classes including the major research project. It was also demanding to work on our research because of the huge amount of work load." (JLU Interviewee Number 1, January 2020)

"My first semester was like difficult because I was not yet used to the university systems and teaching methods. I was like a bit shocked because university and school are quite different, not the same at all so I needed some time to adjust but then the second semester I started to find my feet I really started to get into university life" (NWU Interviewee Number 1, February 2020)

"Their classroom discussions were more like debate and it was a bit difficult at first. In general, I was partly satisfied with my academic performance. It was challenging I must admit. But my second semester was pretty amazing because I was already used to the lectures teaching methods, and the type of exercises they would give out. I was familiar with quite a lot of things" (JLU Interviewee Number 2, January 2020)

Despite the common views raised about teaching methods, some respondents from JLU acknowledged that, even though it was their first time studying abroad, it was their responsibility to adapt. Respondents alluded to the fact that being a student at JLU took her out of her comfort zone, whilst another acknowledged that lecturers assisted them in adapting to the learning environments. The majority of international racial minority students at JLU performed very well in their home countries. However, transition to a new country can negatively affect the student's grades. Findings also revealed that due to the COVID-19 epidemic, racial minority students learnt through digital distance learning via virtual classes. This did not lead to racial minority students in either contexts to interact with students from the majority racial groups beyond the virtual classes. Furthermore, findings also showed that racial minority students from both contexts face similar academic challenges such as pressure to obtain good grades, meeting deadlines, attending classes, test or exam-related anxiety, as well as getting along with classmates from the dominant group.

\subsubsection{Interaction with the Racial Majority Students or Outgroup}

Interaction with the racial majority group seemed to be important to both JLU and NWU students. These interactions assist students to adapt to new campus environments. The following research participants commented on the difficulty associated with establishing friendships with students from the majority group:

"There was a gap between us and the majority group. I think most of the minority students took German course to be able to communicate and interact with the German students. We never used German that much because we used English in our classed. We never got a chance to meet them except in the cafeteria, library, and computer labs. It could be, most German students attended activities outside the campus, I mean they knew the town more than us. Some of the racial minority students could not speak fluent English so it was a bit difficult to interact even amongst the racial minority group. Some of these students speak Spanish and French" (JLU Interviewee Number 6, January 2020)

"Most of my interactions were with international students. Most of the racial dominant students would interact with students of the same race; it was hard to connect with them. However, some of course some were friendly. I connected more with international students of a similar race to mine. I actually do not have German friends (JLU Interviewee Number 5, January 2020) 
"It is much easier interacting students who share similar characteristics as you such as race, gender and sometimes age. You understand each other better because of the social cultural beliefs that you share. These interactions go beyond the classroom, even to the place of residents. In the academic spaces, sometimes we are not given a choice in choosing group members. The groups encompass of classmates from the majority group, but definitely, this is only for academic purposes only. In class activities where we are asked to choose our own groups, most students group themselves with students from the same race and sometimes gender" (NWU Interviewee Number 4, February 2020)

Racial minority Students from the JLU has difficulty interacting with the racial majority students. Friendship establishment with the outgroup from both institutions appeared to be difficult as both students indicated they did not have any close relationships with the majority of students. Most racial minority students are not familiar with the cultural practices of their fellow students. They might have stereotypical views about other racial groups; this was even worsened by the COVID-19 regulations. Students from JLU and NWU had limited opportunities to interact with students from the outgroup as classes were moved from in person to virtual classes. Cultural barriers may breed a sense of loneliness, tension, isolation and helplessness. Students from both contexts also mentioned that at the initial stage of interaction, they had higher levels of anxiety and uncertainty leading to difficulty in interacting well with the racial outgroup. Another important point to note was that any interaction with the majority of students was based on academic purposes rather than social interactions. Based on the JLU and NWU respondents, more friendships were established with those of similar characteristics. Moreover, racial minority students limited their social circles based on shared characteristics. It is possible to experience misunderstandings due to stereotypical beliefs that people have about other social identities which some students possess (race, gender, and ethnicity). This then supports their decision to choose interactions with racial groups that share similar characteristics.

\subsubsection{Environmental and Living Conditions}

Environment and living conditions played a significant role in the overall experiences of students on campus. Students who lived in campus residence were more likely performance better in their academics than those who live off-campus. Findings indicated that most students from JLU complained that staying in the campus residence caused cultural and language shock. Consequently, this led to academic and social withdrawal. One respondent indicated that she was always worried about hygiene at the residence she was staying in. Whereas at NWU, all students indicated they preferred staying off-campus because was convenient and not expensive as the residence. Results also showed that students who live on campus residence attended classes more frequently as compared to those who stay at home or off-campus. The following racial minority student mentioned,

"We were not impressed, you know students from different races meet, they clash because of cultural and language differences. If I had to rate the accommodation in a scale of 1 to 10, I would give it a 4. It was not really not a pleasant experience, but there were no racism experiences, it's just that when students are not from the same cultures they have differences in our cultural norms and values" (JLU Interviewee Number 7, January 2020)

Findings indicated that students in the JLU live in residential halls unlike students at NWU who preferred to stay off-campus. The racial minority students indicated encountering challenges such as conflict with roommates, and personal matters. They revealed experiencing challenges in their dormitories. Approximately, $70 \%$ of racial minority students outlined that they spent most of their time in their dormitories either studying, sleeping or socialising primarily with roommates. With NWU, racial minority students prefer to reside off campus to avoid racism, discrimination and being stared at when arriving at particular facilities. Furthermore, students reported the prevalence of racial slurs in shared spaces within the campus facilities.

The following section will discuss the findings of the study

\section{Discussion of Findings}

Empirical findings from the study revealed that racial minority students had different experiences concerning the sources of racial slurs and micro-aggressions. At JLU, the main sources of racial slurs were fellow students whereas at North West University, racial incidents were from staff members. The reason might be both the perpetrators of JLU and NWU were not aware that they were causing harm to the victims. These findings are similar to the ideas advanced by Reid \& Radhakrishnan (2003); Loo \& Rolison, (1994); Moore et al. (2008); Lo et al. (2017) and Okusolubo (2018). These scholars are of the view that RMS are more likely to encounter difficulties in higher education. Findings are also in line with Sue et al. 's (2007) argument that perpetrators of racial micro-aggressions are sometimes unaware that their questions or actions inflict others negatively.

In addition, our study findings indicated that racial minority students found it more difficult to adapt in the host country in the context of a dominant majority group. Sam and Berry, (2006) and Berry (2005) argued that the changes that 
racial minority students undergo affects their adjustments in the host country or context. The individual psychological wellbeing are affected due to multiple stressors that affect the racial minority students' adjustment to the new learning context. The acculturation that these racial minority students experience within the dominant group can lead to acc]ulturative stress and culture shock (Sam and Berry, 2006).

In the COVID-19 context, there were limited opportunities for both JLU and NWU racial minority groups of creating relations with students from the dominant group. This was due to all learning activities moving from person to person towards hybrid or online learning. Findings are in line with Herley \& Merlinda (2020), Olironin \& Uleanya (2021), Sharii and Khavarian-Garmsir (2020) who advanced the notion that due to the COVID-19 restrictions put in place transformed interactions existing amongst students. Learning became more digitalised and hybrid. Racial minority were presented with limited opportunities to create a sense of belonging with the dominant group.

Further, findings indicated that although racial minority from both contexts had difficulties in adapting to the "local" language in both contexts, racial minority students had to enrol in the compulsory German course unlike students at NWU. It is important to note the interface between language and race creates a vicious cycle of power, dominance as long-lasting effects of colonialism. Despite the fact that the white were a RMS in the southern context, they were not compelled to enrol in the Bantu language courses. English was the standard language unlike in JLU, the education knowledge and instructional dominant language created class divides between the racial minority group and the racially dominant group. The South African education system is racialised and Ngalo-Morrison (2017: 125) argued that student protests in South African institutions in 2015 and 2016 raised concerns of racially excluding practices illustrated in Eurocentric referenced curricula, staff appointments and even artefacts which they see as academy-related obstructions, hence the \#RhodesMustFall campaign". This points to how racism within the North-West University is embedded in the socio-historical contexts of white supremacy, a privilege that further worsens the situation of racial minority students. However, it must be noted that racial minority students at NWU were experiencing racist incidences because of the perceptions that the majority groups held of racial hierarchies that not only exist in institutions of higher learning but in almost all systems. Findings also revealed that the COVID-19 restrictions put in place led to racial minority students in both contexts to experience barriers in navigating amongst the dominant languages curtailed their opportunities to interact using dominant languages. These results are in line with Choi \& Chiu (2021) who argued that the pandemic aggravated gaps of linguistic minority students of adapting to dominant languages and cultures due to remote learning.

Results from the study show that although racial minority students were of varying contexts, they experienced similar difficulties in adapting to new cultural norms of the racial dominant groups in both institutions. Racial minority shared similar experiences citing feeling of loneliness, frustration and helplessness especially upon arrival. For this reason, the adjustment required effort because without it, it was possible to cause discomfort and affect mental health. Titel (2009) reports that minority students in higher education systems are strained because they have to adapt to new norms, values, traditions and the racial dominant languages. The president of the Deutscher Akademischer Austauschdienst German: German Academic Exchange Services (DAAD) indicated that, the dropout rates of international racial minority students is relatively high, accounting to $41 \%$ of the dropout rate. This was perceived as a failure of higher institutions to retaining and assisting racial minority students to adjust to new campus cultures and dealing with culture shock. It is also important to note that improving support services and counselling services would help lower the attrition rates that occur as a result of cultural shock in universities.

The move to remote learning due to COVID-19 has revealed cultural and linguistic challenges for racial minority students in northern and southern contexts. Findings confirm the notion that student experiences in higher education during pandemics can vary due to complexities and multiple social identities in this case (nationality and race) which pose differences in agency, power and status (Bidwell et al, 2021; Collins and Bilge, 2020). These may hinder racial minority students' experiences in educational spaces. With these social identities, coupled with psychosocial stress, financial constraints, gendered responsibilities, racial minority may be marginalized in their social and academic spaces.

Racial minority students in both JLU and NWU struggled to competently study in the first year of enrolment. The results of this study were consistent with the work of Mahlangu (2017) who found that the key aspect to RMS's performance is in line with their level of adjustment to their universities. The participants of the study conducted by Mahlangu (2017) attested to struggling to adjust in the first term enrolment. Nonetheless, this meant that racial minority students' adaptation patterns are essential to institutions of higher learning, as it enable them (racial minority students) to deal with the challenges they might encounter on campus. 
Similarities were found in terms of minority student experiences establishing friendships with students from the majority groups in both institutions before and during COVID-19. At NWU, this was attributable to the fact that the minority students were white and Indian, thus their white privilege from historic and race biases afforded them a superior status within the academic context. On the other and non-white students who belonged to the minority group at JLU had difficulty in based on the same notion, but in this case applicable to the majority. Racial historical legacy in higher institutions of learning is associated with power, status and superiority, thus affecting the interaction that exists between different races within the academic context. In other words, racial power influences higher education systems and influences the social and academic experiences of racial minority students in varying contexts. Results are consistent with Ancis et al. (2000) and Morshedi (2011) who were of the viewpoint that students were interacting with the ones who shared similar characteristics. Zhao, et al. (2005) is of the viewpoint that the possible reasons for each racial group preferring to interact with peers from the same racial group might be attributable to the fact that they share similar values, ideas, norms and cultural practices. Furthermore, Strayhorn (2017) who found that same-race support played a major role in racial minority student's experiences. Students would benefit from same-racial peer support when they encounter challenges. Peer support comes in form of empathy, understanding and fostering resilience to other racial minority students as they can relate to similar racial incidents they experience. Morshedi (2011) found that the lack of interaction between the racial dominant groups and racial minority students results in feelings of otherness and alienation for the latter group. Morshedi (2017) further adds that, racial minority students should refrain from interacting only with those who they share similar characteristics with; rather, they must interact with members outside their racial groups.

In addition, the study findings also reveal that both racial minority students in Justus-Liebig University and North-West University experienced academic stress due to high workloads and adaption to the new academic contexts during their first semester. Their lack of formal and informal interaction with the student majority groups consequently affected their integration, thus leading to either positive or negative experiences. The positive experiences helped with integration as opposed to negative experiences that cause students to dropout, as Tinto (1993) argues that negative experiences lead to high rates of dropout.

To support these findings, Mahlangu (2017) argued that students have different characteristics and different attitudes toward their studies. Most of the students revealed signs of stress to new teaching and learning methods in their respective universities. Chai and Low (2015) are of the view that minority students need to employ coping strategies, which involved effective planning, peer support and putting support structures that assist to deal with racial challenges encountered. In contrast to the findings of this study, Zhao et al., (2005) highlighted that racial minority students were able to cope with the academic demands and other stressful life events better when compared to the host students.

Findings also indicated that COVID-19 presented a different set of challenges for racial minority students. Due to the closure of residences, some international racial minority students had to seek refuge from close friends if not from the government. The results are in line with Oliranin and Uleanya (2021) who also argued that other students were faced with the challenge to arrange traveling back home at a short notice. While most students residing in campus had to return home, this also had an impact on those residing off-campus Oliranin and Uleanya, 2021). A point to note is that most students were pressured to go home, were those who resided in campus than those staying off-campus.

The results of this study were consistent with the work of Wayt (2012) who found out that racial minority students need time to deal with the transitions of moving from one environment to another. The findings of this study also revealed that there was a difference in environmental adapting behaviour between the JLU and NWU students. Students at JLU indicated the need of getting used to the campus environment, language, academic standard and culture shock compared to the North-West University students, respondents who indicated that they more aware of the racial dominant cultures. Interestingly, racial minority lacking the cultural socialisation with the majority students did not affect them negatively to the extent of resorting to withdrawal from the institution; this did not affect their interaction with other minority students. However, this experience influenced racial minority in both JLU and NWU to be comfortable with other minority students of a similar racial group.

\section{Conclusions and Recommendations of the Study}

In conclusion, the study aimed to investigate the challenges faced by students in Justus-lieberg University in Germany and North West University in South Africa. Respondents from both institutions raised their concerns about the majority-minority gap that existed. Most Justus-Liebig University respondents indicated friendship establishment with other racial minority students as compared to those of the host country whereas, respondents at North-West University indicated close relationships mostly with students of the same racial backgrounds. Interestingly, North-West University students did not express the gap between them and the majority students as much as the 
respondents at Justus-Liebig University did. Rather students at North-West University indicated that they gravitated towards those of same racial background.

Both Justus-Liebig University and North-West University respondents expressed their negative and positive experiences on academic expectations. Most students indicated the first semester as the worst as they were still in transition mode of getting used to the different education systems. Respondents' from North-West University's major transition was from high school to university. Respondents had different expectations from teaching methods, grading system, calculations of semester marks caused difficulties in adapting the teaching and learning methods of higher education systems.

Based on the empirical results, this paper recommends that:

- Institutions of higher learning are racially diverse and each student holds different perceptions toward other racial groups. This study recommends that institutions of higher learning deal with racial minority students as victims of discrimination, racism and alienation because it is possible for racial minority students to develop racial attitudes towards other students.

- All structures of the university (Student religious organizations, Student Representative Committees, Institutional offices, peer groups, Academics and support staff) need to work together to ensure friendly campus climates for students from varying races, genders, age and ethnic groups.

- Policies should be put in place to ensure that occurrences of racism are dealt with at all structural levels.

- Awareness programs need to be initiated through seminars, conferences, orientations for all campus populations to promote inclusive, diverse and socially just campuses.

- Institutions of higher learning should invest in formal and informal programs such as mentorship, support groups and social support networks to mediate student's expectations and integrate all minority students whether by race, ethnicity and nationality.

- Institutions of higher learning should create programs that encourage students to participate in both social and academic programs. This should aid and improve retention rates and students should be part of all the diversity-related college activities.

- Racial minority students at JLU and NWU respondents spoke of their desire to integrate and build close relationships with the host students. This study is a clear indication of the need for institutions to encourage peer learning and programs that support the integration of majority students with minority students.

- There is a need for institutions to enact support structures that encourage seminars, tutorial sessions and career guidance where both majority and minority students are involved. This would lead to more social and academic integration of minority students in IHL.

\section{References}

Ancis, J. R., Sedlacek, W. E., \& Mohr, J. J. (2000). Student perceptions of campus cultural climate by race. Journal of Counseling and Development, 78(2), 180-185. https://doi.org/10.1002/j.1556-6676.2000.tb02576.x

Bidwell, L. M., Grether, S. T., \& Pederson, J. (2021) Disruption and difficulty: Student and faculty perceptions of the transition to online instruction in the COVID-19 pandemic. In: Ryan, JM (ed.) COVID-19: Social Consequences and Cultural Adaptations. New York: Routledge, 31-46. https://doi.org/10.4324/9781003142065-5

Berry, J. W. (2005). Acculturation: Living successfully in two cultures. International Journal of Intercultural Relations, 29(6), 697-712. https://doi.org/10.1016/j.ijintrel.2005.07.013

Castleberry, A., \& A. Nolen. (2018). "Thematic analysis of qualitative research data: Is it as easy as it sounds?" Currents in Pharmacy Teaching and Learning, 10(6), 807-815. https://doi.org/10.1016/j.cptl.2018.03.019

Chai, M. S., \& Low, C. S. (2015). Personality, Coping and Stress Among University Students. American Journal of Applied Psychology, 4(3), 33-38. https://doi.org/10.11648/j.ajap.s.2015040301.16

Choi, T. H., \& Chiu, M. M. (2021). Toward equitable education in the context of a pandemic: supporting linguistic minority students during remote learning. International Journal of Comparative Education and Development. https://doi.org/10.1108/IJCED-10-2020-0065

Collins, P. H., \& Bilge, S. (2020). Intersectionality. Cambridge: Polity Press. 
Etikan, I., Abubakar, M., \& Alkassim, K. S. (2016). Comparison of convenience sampling and Purposive sampling. American Journal of Theoretical and Applied Statistics, 5(1), 1-4. https://doi.org/10.11648/j.ajtas.20160501.11

Feredi, F. (2015). Microaggression theory: an assault on everyday life. Available at: https://www.spiked-online.com/2015/11/23/microaggression-theory-an-assault-on-everyday-life/ Date of access: 21 May 2019.

Ispa-Landa, S., \& Conwell, J. (2015). “Once You Go to a White School, You Kind of Adapt” Black Adolescents and the Racial Classification of Schools. Sociology of Education, $88(1)$, 1-19. https://doi.org/10.1177/0038040714555434

Jansen, J. (2015). Racism on campus: Jumping around "like Mad Hatters". Available at: http://www.thejournalist.org.za/spotlight/racism-jump-around-like-mad/hatters

Jayakumar, U. M. (2015). Why are all the Black students still sitting together in the proverbial college cafeteria: A look at research informing the figurative question being taken by the Supreme Court in Fisher, Los Angeles. Higher Education Research Institute At UCLA. https://escholarships.org/uc/item/9xx381wt

Lo, C. C., McCallum, D. M., Hughes, M., Smith, G. P., \& McKnight, U. (2017). Racial differences in college students' assessments of campus race relations. Journal of College Student Development, 58, $247-263$. https://doi.org/10.1353/csd.2017.0018

Loo, C. M., \& Rolison, G. (1994). Alienation of ethnic minority students at a predominantly white university. Research Gate: Hawaiioo. https://doi.org/10.1080/00221546.1986.11778749

Mahlangu, T. K. (2016). The academic experiences of Grade 12 top achievers in maintaining in first-year university programme. PHD Thesis. University of Pretoria: South Africa. https://doi.org/10.20853/31-1-812

Marmer, E., Marmer, D., Hitomi, L., \& Sow, P. (2010). Racism and the image of Africa in German schools and textbooks. International Journal of Diversity in Organizations, Communities and Nations, 10(5), 1-12. https://doi.org/10.18848/1447-9532/CGP/v10i05/38927

Moore, J. V., Hossler, D., Zuskin, M., \& Wakhungu, P. K. (2008). Institutional factors that contribute to student Persistence: Views from three campuses. (In Annual Conference of the Association for the Study of Higher Education, Indiana University: Bloomington. p.1-48).

Morshedi, A., \& Hassan, G. (2011). Academic socialization: A comparative study of the experiences of the Emirati and Saudi students at US universities. Pennsylvania: The Pennsylvania State University. (Dissertation-PhD). https://etda.libraries.psu.edu/files/final_submissions/2030

Ngalo-Morrison, L. (2017). Factors influencing the academic attainment of undergraduate sponsored students at the University of the Western Cape: A strength-based approach (Doctoral dissertation, University of the Western Cape: South Africa). https://etd.uwc.ac.za/bitstream/handle/11394/5553/morrison_phd_edu_2017.pdf?sequence=1\&isAllowed=y

Nowell, L. S., Norris, J. M., White, D. E., \& Moules, N. J. (2017) Thematic Analysis: Striving to Meet the Trustworthiness Criteria. International Journal of Qualitative Methods, 16, 1-13. https://doi.org/10.1177/1609406917733847

NWU (North-West University). (2017). Student statistics of the NWU Mafikeng Campus: Management information report Available http://www.nwu.ac.za/sites/www.nwu.ac.za.files/files/stud_stats/GR_student_statistics_of_the_NWU_Mafiken g_Campus.pdf Date of access: 25 May 2017

Odhav, K. (2009). South African post-apartheid Higher Education policy and its marginalisations:1994-2002. Available https://www.semanticscholar.org/paper/SouthAfricanpostapartheidHigherEducationand\%3AOdhav/49bd4787fd fefd7094f0c6b533458d7c1a98fe29 Date of access 3 September 2020

Okusolubo, G. (2018). Academic and Social Challenges Faced by African International Students in Collegiate institutions in America. International Journal of Economics \& Management Sciences. https://doi.org/10.4172/2162-6359.1000514

Olaniran, S. O., \& Uleanye, C. (2021) The Effects if COVID-19 in International Students in South Africa. International Journal of Innovation, Creativity and Changes, 15(4), 2021. https://www.researchgate.net/publication/350966924_ 
Pandher, N. (2017). Racial Microaggressions on an Online Anonymous Platform. Honors College Theses. 24. Available at: https://digitalcommons.wayne.edu/honorstheses/24 Date of acceess:20 September 2018

Reid, L. D., \& Radhakrishnan, P. (2003). Race matters: The relation between race and general campus climate. Cultural Diversity and Ethnic Minority Psychology, 9(3), 263-275. https://doi.org/10.1037/1099-9809.9.3.263

Ritter, Z. S. (2016). International Students Perceptions of Race and Socio-Economic Status in an American Higher Education Landscape. Journal of International Students, 6(2), 367-393. https://doi.org/10.32674/jis.v6i2.362

Sam, D. L., \& Berry, J. W. (Eds.). (2006). The Cambridge handbook of acculturation psychology. Cambridge University Press. https://doi.org/10.1017/CBO9780511489891

Solozano, D., Ceja, M., \& Yosso, T. (2001). Critical race theory, and racial microaggression and campus racial climate: The experience of African American students. Journal of Nigro Education, 69(1). https://www.middlesex.mass.edu/RLOs/748/Critical-Race-Theory.pdf

Strayhorn, T. L. (2017). Factors that influence the persistence and success of Black men in urban public universities. Urban Education, 52(9), 1106-1128. https://doi.org/10.1177/0042085915623347

Sue, D. W., Capodilupo, C. M., Torino, G. C., Bucceri, J. M., Holder, A. M. B., Nadal, K. L., \& Esquilin, M. (2007). Racial microaggressions in everyday life: Implications for clinical practice. American Psychologist, 62(4), 271-286. https://doi.org/10.1037/0003-066X.62.4.271

Tinto, V. (1993). Leaving college: Rethinking the causes and cures of student attrition. 2nd ed. Chicago: University of Chicago Press. https://doi.org/10.7208/chicago/9780226922461.001.0001

Titel, W. (2009). Cultural experiences of German and Chinese exchange students and implications for a target group-orientated intercultural training programme. (Dissertation)

Wayt, L. (2012). The impact of students' academic and social relationships on college student's persistence. Nebraska: University of Nebraska. (Dissertation-Masters).

Zhao, C. M., Kuh, G. D., \& Carini, R. M. (2005). A comparison of international student and American student engagement in effective educational practices. The Journal of Higher Education, 76(2), 209-231. https://doi.org/10.1080/00221546.2005.11778911

\section{Copyrights}

Copyright for this article is retained by the author(s), with first publication rights granted to the journal.

This is an open-access article distributed under the terms and conditions of the Creative Commons Attribution license (http://creativecommons.org/licenses/by/4.0/). 